Article

\title{
Brand New Images? Implications of Instagram Photography for Place Branding
}

\author{
Åsa Thelander * and Cecilia Cassinger \\ Department of Strategic Communication, Lund University, 23733 Helsingborg, Sweden; E-Mails: asa.thelander@isk.lu.se \\ (Å.S.), cecilia.cassinger@isk.lu.se (C.C.) \\ * Corresponding author
}

Submitted: 27 May 2017 | Accepted: 28 August 2017 | Published: 21 December 2017

\begin{abstract}
The aim of this article is to develop an understanding of what happens when Instagram photography is used for branding a place. Questions raised are which photographs are taken and published, does the practice result in novel ways of representing a place, and, in turn the image of a place. A practice approach to photography is used where focus is directed to the performative aspect of photography. Fifteen qualitative interviews were conducted with participants in an Instagram takeover project concerning their photographs. The study shows that adopting a communication strategy based on visual social media is dependent on the participants' competencies and that it is embedded in everyday life. Moreover, the participants' photographic practices were found to be influenced by social conventions, which resulted in the city being imagined differently by different participants. To use visual social media such as Instagram for branding purposes does not necessarily mean that novel images are generated, but that they are choreographed according to the conditions of Instagram as medium.
\end{abstract}

\section{Keywords}

Instagram; photography; place branding; practice; social media; strategic communication; visual

\section{Issue}

This article is part of the issue "Visual Communication in the Age of Social Media: Conceptual, Theoretical and Methodological Challenges", edited by Uta Russmann (FHWien der WKW University of Applied Sciences for Management \& Communication, Austria) and Jakob Svensson (Malmö University, Sweden).

(C) 2017 by the authors; licensee Cogitatio (Lisbon, Portugal). This article is licensed under a Creative Commons Attribution 4.0 International License (CC BY).

\section{Introduction}

Place branding strategies commonly incorporate visual social media to promote favorable, or counter negative, images of cities, regions and nations (Braun, Kavaratzis, \& Zenker, 2013). Visual social media applications and smartphones enable non-professionals to produce their own images of the city which are assumed to provide a more authentic and innovative image of a place than professional photographs produced for strategic reasons. There are great expectations regarding the effects of visual social media campaigns on citizen engagement in community life and to change and improve the image of a city. For instance, the Swedish municipality of Land- skrona seeks to alter negative images of the city of Landskrona through a so-called Instagram takeover, in which a different citizen manages the account each week to represent his or her view of the city.

Strategies in which everyday practice is used for a particular aim are increasingly used to promote places, but, so far, critical examinations of such strategies are rare. To a great extent, place brands tend to be understood through visual artefacts. The problem is, however, as Kavaratzis $(2009$, p. 27) points out, that the visual is commonly understood as "elements of branding such as the incorporation of a new slogan and, at best, the design of advertising campaigns around those visual elements". In contrast, the concern of this article is not with the rep- 
resentational aspects of a place brand, but with gaining understanding of the change in power dynamics with regards to how such representations are produced. Practices on visual social media platforms challenge the distinction between professional and amateur and strategic and non-strategic. In order to explore this particular dynamic, this article is informed by practice theory taking into account the individual, social and technical aspects of how photos are taken and shared. The most distinguishing feature of the Instagram platform, for instance, is that it enables non-professional actors to enhance photos by adding a filter that gives them a glow and makes them appear professional. In Instagram takeovers, participants use media that they are familiar with, and draw on previous experiences and practices embedded in everyday life.

The aim of this article is to develop an understanding of how non-professional images are produced and used in the photo-sharing platform Instagram for strategic purposes to strengthen a place brand. The study is based on a single case of a city branding campaign involving Instagram-takeover in the Swedish municipality of Landskrona. The study contributes with knowledge on how everyday photography is included in communication strategies and what it means for the practice. Moreover, the study also contributes with glimpses of an emerging Instagram culture of taking and sharing images of place brands and the changing power between communication professionals and laymen in forming and sustaining a place image.

\section{Theoretical Framework}

In previous research, photography has predominantly been approached from a representational perspective, i.e. focusing on how photographs reflect ideas, visions and places, etc. Less attention has been paid to the practice of taking and sharing photographs. The practice turn has influenced many other fields of studies for instance organizational studies, tourist studies, consumer studies, but has been relatively absent from studies of photography (Gomez Cruz \& Lehmuskallio, 2016). However, the benefits of applying this approach to further the understanding of photography has been emphasized by several researchers (see for instance Chalfen, 2016; Gomez Cruz \& Lehmuskallio, 2016; Pink, 2011; Van House, 2011). Research adopting a practice approach to photography is generally underpinned by a few basic assumptions, such as the role of structure for agency, the performativity of social life, that practices are collectively organized and coordinated by shared understandings, procedures and engagements, and that practices are relational and change over time. A few notable examples of studies that approach photography from a practice perspective can be found within sociology of consumption research tradition (Shove, Watson, Hand, \& Ingram, 2007) and research informed by science and technology studies (STS) (Van House, 2009). Drawing on a combination of STS and non-representational geography (Thrift, 1999),
Larsen (2008) argues that everyday photography converges with tourist photography, which he broadly defines as an embodied social performance and "leisurely picturing practices conducted away from home" (p. 143). He further states that tourist photography is "bound up with performing social relations" turning places into "dramaturgical landscapes" and that digital tourist photography is "networked with everyday communication technologies" (Larsen, 2008, p. 143). In line with Larsen (2008), this study is concerned with the hybrid practices of photography and not the photographs. The focus of research is thus the doings of digital or smartphone photography and in particular the material production, display, and circulation of photographs. Digital photography is here viewed as, to quote Larsen (2008) once more, a "complex amalgam of technology, discourse, and practice" (p. 143; see also Orlikowski, 2007; Schatzki, 1996). In addition, to take photographs with a smartphone is a practice that is often enacted in the course of everyday life guided by social conventions and norms. Hence, photographic practice is viewed as combinations of mental frames, artefacts, technology, discourse, values and symbols (Orlikowski, 2007; Schatzki, 1996). A particular combination of these different building blocks constitutes practice, which can be captured through the "routinized ways in which bodies are moved, objects are handled, subjects are treated, things are described and the world is understood" (Reckwitz, 2002, p. 250, in Postill, 2010). Edensor writes that "When stepping into particular stages, preexisting discursive, practical, embodied norms and concrete guiding by guides and signs usually choreograph tourists" (Edensor, 2001, p. 71). The practice studied here, to take photographs for instrumental purposes and publish them on an official and open Instagram account means that an everyday practice is put into a new context. We do not know if and which "pre-existing discursive, practical, embodied norms" guide the participants' practice.

\subsection{Photography as Everyday Practice}

In order to understand digital photography as everyday practice we have turned to a classical study of how private family photo albums are produced (Chalfen, 1987). Chalfen (1987) argues that photographs are embedded in a communication process that includes five communication events that must be taken into consideration when analyzing photography. Hence, it is a communicative perspective on practices of picturing. First, the planning event which involves when photographs should be made, who makes them, what kind of equipment is used, what kind of preparation in terms of knowledge is needed for taking photographs. Second, on camera shooting includes the camera technique. Third, behind the camera shooting, means who is included or excluded from a photograph, the kind of settings, environments, activities, events, systematic arrangements, posing, social relationships, verbal instructions used in order to get 
a feeling of managed presentations. Fourth, the editing event, if and how images are arranged or rearranged and finally, the exhibition event, how it is socially organized, who initiates it, promotes or restricts it and when it takes place. The components can be used to describe the operation and how an impression and event are formed into a visual code-the photograph.

The communicative events developed by Chalfen (1987) concern analogue photography but there are reasons to believe that the communicative events are relevant when digital technology is used. Chalfen (2002) states that camera technology does not control the practice. However, conditions for the activities are different. Van House (2011) concludes that more photographs are taken. Prior planning is reduced and photographs are taken more spontaneously, particularly when camera phones and smartphones are used. Everyday life situations are being photographed, so what is regarded as photo worthy has changed. Software makes it possible to easily change, remove and improve photographs. New technology makes it possible to archive large numbers of photographs. It is also possible to share photographs to an extent that has never previously been possible. Given these facts, researchers tend to overemphasize the changes due to new technology. New functions and behavior are claimed to have replaced old ones. They appear as new media and imply new behavior, which is in sharp contrast to and different from previous practices. However, empirical studies of photography (Pink, 2011) point to the fact that "old" ideas, practices and technique are integrated or exist parallel to the new ones.

Digital photography has also been paired with social media applications such as Instagram. Instagram allows the user to instantly share their images on a social networking site. Moreover, it provides the user with a number of digital photographic filters to use and possibilities for other manipulations, for instance cropping. It provides the user with easily used tools but it is also a constrained environment (Zappavigna, 2016) as there are restrictions, for instance, on image dimension. The types of image created have been studied and several scholars have pointed out that the "selfie" is the most common type of image (Dinhopl \& Gretzel, 2016). Dinhopl and Gretzel (2016) suggest that selfietaking, which is a social media related practice, has consequences for photography in other domains of life, i.e. tourist photography. The focus of tourist photography has moved from the extra-ordinary to a focus on social relations and a shift towards the personal to self-expression and identity formation. Hence, photography practice takes place in a networked society, and is influenced by social media practices. So far there are few studies of the role of Instagram for photographic practice.

\section{Methodology and Empirical Material}

This study is focused on photographic practices used for visual social media and their role for strengthen a place brand. Interviews are used, as expression about action is important, and to elucidate how the participants make meaning of the photo task. Before giving a more in-depth presentation of the interviews and the analysis, the case will be presented.

\subsection{An Instagram Takeover Project}

This study is based on an Instagram takeover project carried out by the mid-sized Swedish city Landskrona, situated on the south-west coast of Sweden. Like many other European cities formerly dominated by shipbuilding, the city has been forced to find alternative industries and new values for its identity. Social problems are well documented and a few incidents (assaults and honor killings) have gained enormous negative media attention. A study carried out in 2012 by the city administration, revealed that common associations of Landskrona, among those living and working there, were unemployment, criminality and multiculturalism. In order to improve the city's reputation, a social media initiative was launched on December 3, 2012. The official Instagram account of the city is controlled by a different citizen each week to portray the city through his or her images.

Participants are recruited on a voluntary basis. Instructions for the participants are few, but have been developed during the progress of the project. Initially, restrictions on photographing people were communicated.

The project is anticipated to increase engagement and participation in city life among local actors, ultimately generating more positive associations of Landskrona city. Representations are expected to be personal and more of an inside perspective.

\subsection{Photo-Elicitation Interviews}

In-depth interviews were carried out with participants in the project. The photographs the participants had taken and published on the official Instagram account served as input for the interviews. The procedure can be defined as photo-elicitation interviewing, implying that the photographs are important for the conversation but they are not analyzed per se (Clark-Ibanez, 2004). The experience of partaking and how the participants plan and perform the task were discussed. The communicative events defined by Chalfen were included. To acknowledge the role of structure, we asked explicitly about experience of the technology (digital cameras, Instagram and other social and visual media). Questions about conventions were asked and the interviewees also spontaneously discussed "normal" behavior and, explicitly, dos and don'ts. The guided conversation took from 45 minutes up to one hour depending on the number of photographs the interviewee had taken. All interviews were recorded and have been transcribed.

The Instagram takeover project had been running for eight months when the interviews were carried out. Almost thirty citizens had participated. Half of this group 
were selected for an interview. In order to be able to understand practice and different practices we wanted a heterogeneous group of interviewees, i.e. a strategic selection. Participants of different ages were selected as this can indicate different experiences of photography and familiarity with social media. Participants with obviously different ways of representing the city were selected. The result was that fifteen participants were contacted, and they all agreed to an interview.

The analysis can be described as taking place in three steps, i.e. categorization, comparison, dimensionalization (Spiggle, 1994). The communicative events developed by Chalfen (1987) functioned as a frame for the analysis while the meaning and performance of the different steps were derived from the interviews. There were also ideas we had not foreseen that informed the analysis. For instance, the well-articulated guiding principles for their performance were unexpected, and therefore the analysis was expanded to cater for this important aspect. Hence, categories were formed based on theory as well as derived from the interviews.

Those categories were compared and organized, i.e. dimensionalization has been made. The different codes were grouped into more conceptual classes; categories were made (Spiggle, 1994). Differences were compared to form ideal types. Ideal types are defined by Weber as an abstract analytical construct, which will never be discovered in this specific form (Aronovitch, 2012). Ideal types are constructed and named by the researcher and are based on selected characteristics. The interpretation and way to perform the task as well as ideals used for discussing their way of performing are used for distinguishing between the three ideal types. The point is never to classify individual interviewees to any ideal type rather to present different performances (Halkier, 2011). Hence, unique characteristics and differences are emphasized. To identify and present performance in terms of ideal types is a way to illustrate the social constructed practice of taking photographs.

\section{Practices of Instagram Photography}

From the interviewees' expression about photography we formed three ideal types labelled as the acting tourist, the Instagrammer, and the professional. Below, each ideal type is described and discussed in relation to the overarching aim of reimagining the city. The practice tied to each type is also exemplified by a photograph.

\subsection{The Acting Tourist}

I did not put too much effort into it in terms of planning, but thought I should visit this, this and this. It should not be a boring week....In a way I felt I should show my favorite places. (Ingrid)

The acting tourist performs as vicarious tourists for whom they want to present a favorable image in order to counterbalance the negative reputation of the city. Hence, they perform the activity as being tourists and relate to tourist discourses to make meaning of their practice. Therefore, this ideal type is called acting tourists.

They use their smartphones and seem perfectly fine with using this device, as they normally use it for taking photos. They plan the photo task in advance. An afternoon or daytrip is planned to be able to visit selected places and the activity is often undertaken with a friend.

Their imagined audience comprises citizens and tourists. It is a built image, consisting of landmarks as public reference points which they favour (see Figure 1). They are aware of the fact that landmarks are used in place marketing, but according to themselves, they add a personal touch to these familiar objects by using filters. However, their preferences for the built environment oriented towards older buildings and landmarks means a past temporal orientation. They combine the landmarks with photographs representing activities they appreciate, food and drink for instance. Taken together, it is similar to the combination of photographs used for place marketing (Warnaby, 2015). Moreover, their interpretation of the task and imagined audience resembles the duty of the marketing and communication department of the city. The acting tourist is annoyed by other participants who focus too much on themselves and use the official account for personal branding.

The acting tourist has adopted a realist perspective on photography. This epistemological standpoint guides their practice. According to Chalfen (2002) nonprofessional photographs are guided by evidentiary ideals. Images are made to prove or to reaffirm an event. In this case participants of the project discuss motives

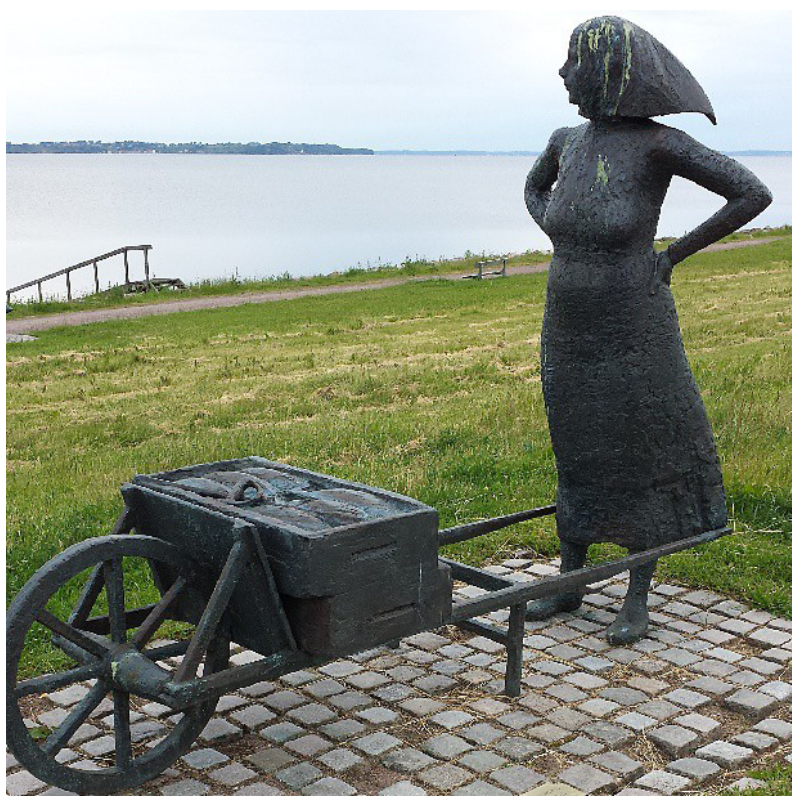

Figure 1. The photographer wants to show the attractiveness of the city by using one of the most famous sculptures in the city. 
and the true nature of the photographs and how the photographs resemble the object. The photographs taken inform about a place.

The acting tourist takes full advantage of digital technique when it comes to taking photographs. In accordance with their ideal, filters are used to improve a positive experience or add a personal touch, but never to the extent that reality is altered. Retro style filters are disliked. The iconic character of photographs guides them and is also an appreciated feature that seems to be important for them.

The possibility to show the positive side means that as many as ninety photographs are published during their week. They are merely variants of the same motives because they are regarded as a way to present a rich image of the city.

To conclude, the acting tourist activates knowledge and experience from being a tourist to perform the photo task. They explicitly compare their photographs to tourist photography and use it as their point of reference and ideal. Hence, it is the practice of tourist they rely on. They have a preference for the picturesque; landscapes and buildings in a past temporal orientation are some of the characteristics. A few of the conventions of the media application are taken into account, for instance the large audience and the ideal of being instant. They expressed their annoyance over participants who published a photograph obviously taken in the winter during the summer. Their past temporal orientation seems to contradict the instant character of Instagram. But for the acting tourist instant is related to when the photograph is taken and published.

\subsection{The Instagrammer}

The private and this task blur. I can easily upload photographs on my work account during the weekend when I am logged in. I have a smartphone and I enjoy using it. You get such a direct response. (Sofia)

The Instagrammer activates knowledge from social media for making sense of the photo task. This group consists of highly experienced social media users. They have several Instagram accounts, for private as well as for professional use. Therefore, the photo task is easily integrated into their everyday use of social media. The smartphone camera is used, which is the equipment they normally use, for taking photographs. Moreover, it is in line with their ideal of instant photography. "Instagram photographs should not be technically perfect".

They want to counterbalance the negative image of Landskrona, but compared with the acting tourist, the Instagrammer focuses on activities and people rather than buildings and picturesque views. They want to contribute to a different view of the city by informing others about on-going projects and events. They want to photograph more of the ordinary practitioners of the city, or to borrow from De Certeau (1984), the elementary form of experience of the city. The function of photography is merely to share a moment based on their self-interest. Hence, their appraisal of mundane worklife distinguishes the Instagrammer from the other types of user. However, the evidentiary role of photographs guides them. They are still taking photographs to inform viewers.

Spontaneous, natural, relaxed and real are words used for describing what they want to achieve. Therefore, they do not plan the photo task. Their preference for the spontaneous and mundane and their acceptance of imperfect photographs are ways to obtain a glimpse of an unexpected view of the city and accomplish authenticity and trustworthiness for their view (see Figure 2). They used filters but reflected on their use of filters and even \#hashtagged photographs with "no filter". In contrast to the other groups, external filters are downloaded. Hence, they are not restricted to Instagram as a service, they take advantage of techniques available in social media.

Facebook is often used as an example of the blurring of boundaries between front and back regions of social lives. Uimonen (2013) claims that this is illusionary, as existing borders are maintained and enforced. Social norms of correct and accepted publication are actualized. The strategists were reluctant to display their private life and did not want to show their friends or family, or details of their private life. Hence, it is a personal but not private image they want to present during their week.

The Instagrammers argue that their main audience consists of followers of the account, i.e. users of Instagram, not necessarily geographically confined to Landskrona. The Instagrammer has the self-imposed objective to increase the number of followers for the account during their week. Based on their experience from Ins-

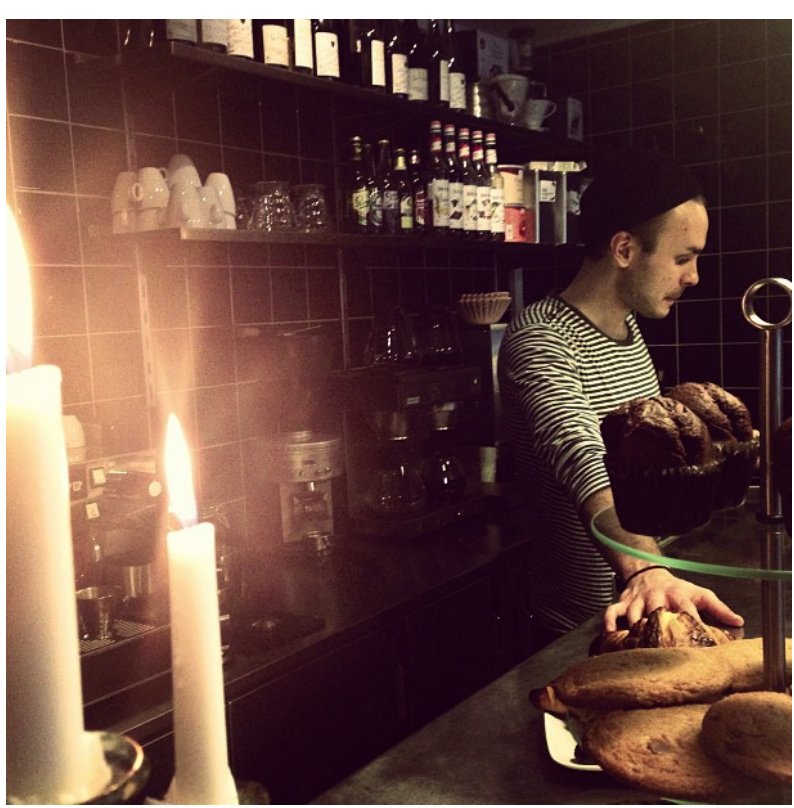

Figure 2. The photographer wants to emphasize positive everyday life in the city. 
tagram and other social media, they apply strategies for increasing the number of followers. Their strategies include using \#hashtags and geotags, i.e. tools are used that are within social media. Social media rules also guide the number of photographs they publish. One per day is their goal, as too many are disturbing for the followers. Moreover, it is unthinkable to publish old photographs.

It is important to generate positive reactions, i.e. likes. They believe it is well-known and picturesque views of Landskrona and photographs of well-known people with many followers that generate likes. They check the account and their photographs several times per day, or every day during their week. It is a kind of immediate feedback on their photographs. On the one hand, likes are stimulating for themselves, and on the other hand likes are seen as a reward for the followers. "You should publish photographs that your followers appreciate". The quest of achieving many likes guides their selection of photographs to publish. Their ideals of photography seem to clash with their self-imposed objective. Therefore, they are not pursuing their idea to present an interesting and personal image of Landskrona, they happen to chase likes and publish photographs attractive for a broad audience. Accordingly, controversial photographs or texts are avoided.

Social media conventions guide their performance and their preferences for photographs. But the fact that the Instagrammer publishes the photographs on an official Instagram account entails ambivalence. The goal to generate likes and increase the number of followers is not compatible with their preferences for the personal, mundane and authentic.

\subsection{The Professional}

My purpose was to be a little subversive and present my picture of Landskrona. I'm quite allergic to doing the same thing as everyone else. But it was not so popular. People thought I was annoying and I did not meet expectations. My photographs did not generate an awful lot of likes. (Johan)

The professional relates the task to their professional knowledge, being a professional photographer. This group is very confident with the task and have a highly individual interpretation and approach to the task.

Their guiding principle is to explore and interpret rather than depicting a place. Some of them have an idea of a theme or themes they want to explore and display (see Figure 3). They do not think in terms of audiences of the Instagram account. They are focused on the photographs and their creation of photographs. The critical eye seems to be an important guiding principle. Moreover, in contrast to the other two types, the professionals make photographs rather than take them (Chalfen, 2002). Their epistemological perspective is different, as they regard photographs, and particularly their photographs, as a construct made by them to evoke a response.
The professionals circumvent the limitations of smartphones and Instagram. They use their professional digital camera for the photo task, as smartphones cameras are considered to be limited and simple. The professional uses all available filters and ways of editing available for the professional. Their use is a careful consideration and is undertaken in regard to what they want to explore and emphasize.

Every photograph published is a careful consideration. If the photograph was taken today, last week or last year it does not matter. The instant character of Instagram is ignored. Their own ideas are privileged. The combinations of photographs during a day are also planned as are the comments to the photographs. They plan their publication as an exhibition.

This group are aware of likes and consider them a bonus. They recognize that their photographs do not follow the conventions of Instagram. The professional expresses opinions and takes a position with their photographs, which seems to be awkward and abnormal for the other ideal types.

Some of the service of Instagram is used, for instance hashtags. But compared to the strategists who use hashtags for increasing interest and number of followers, hashtags are used in a different way. The professional creates their own hashtags, guided by personal ideas, they invent concepts and words. Their aim is to frame the city in a different way. The media application is not about informing or restricting their practice. They take advantage of services, which can be used to further develop their ideas and to explore possibilities with the media.

To conclude, professional photography conventions guide their performance. The ambition is to explore phenomena rather than merely represent.

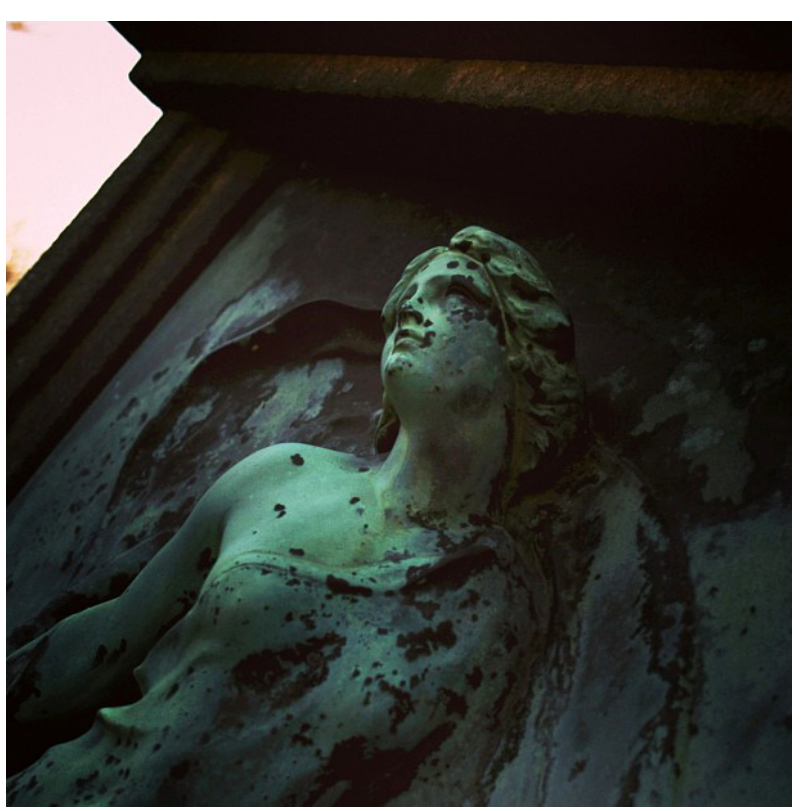

Figure 3. The photographer explored temporality of the city. 


\section{Discussion}

So far, the analysis has been directed towards the micro practice of photography identified by Chalfen (1987). When comparing the different ideal types there are other distinguishing features.

The participants make meaning of the photo task by relating it to their previous experience of photography. Their performance is therefore guided by more general practices.

Their relation to and knowledge about Instagram guides their performance. The acting tourist acknowledges some of the conventions related to Instagram, which seem to have consequences for the photographs they decide to post. Instagram is the true element for the Instagrammer. The professional is aware of Instagram conventions but violates conventions and uses them for their own purposes. The professional regards photography as a way to explore a phenomenon, in this case the image of the city. Their interest in exploring means that they were thinking in a long-time perspective and that they were also future-oriented. Their time orientation is in stark contrast to the acting tourist and the Instagrammer. The acting tourist preferred the constant, stable, well-known, which resembles an orientation to the past, while the strategist was more oriented towards the present.

Different practices, and conventions related to them, seem to inform their ideals of photography. However, common characteristics can be found particularly between the acting tourist and the Instagrammer. Positive aspects of the city are regarded as photo worthy and proper to publish as they think they will generate likes. The distinction between private and public is discussed and the participants avoid being private and political on this account. Consequently, it is the established and wellknown aspects of the city that are posted on the official account.

In this project, the participants draw upon three distinctly different practices, but in other contexts addi- tional practices may be relevant. In a project initiated by the city and with vague instructions some roles may also appear as sanctioned or normal. With the growing number of users of Instagram and increased familiarity with social media we expect that the practice will have more in common with social media than with traditional photography (Van House, 2016).

\section{Conclusions}

The major aim of this article has been to examine how everyday practices of digital photography are mobilized in a place branding campaign involving Instagram takeover to improve a city's image. A performative approach to everyday photography enabled us to understand how photography is enacted and how different social conventions guided the way that citizens curated the city's Instagram account. The communicative events developed by Chalfen (1987) made it possible to distinguish between different performances among the participants, which were called the acting tourist, the Instagrammer and the professional. The acting tourist and the Instagrammer take photographs while the professional makes photographs of the city. These performances were tied to different interpretative repertoires and in part based on participants' previous experiences of photography. Partaking in an Instagram takeover resembles a performance in front of an audience in many ways.

A basic assumption in including everyday digital photography in place branding is to provide a more authentic and trustworthy image of the city. Hence, the expectation in place branding is that citizens' personal performances are put into the public domain through an official Instagram account, which is open for anyone to see. The participants in our study were highly aware of the publicity of their posts and were thus careful with what they posted on the platform. Images of the city produced in Instagram takeovers must therefore be viewed as produced and displayed for a wide audience as imagined by the participants. Consequently, the images of the

Table 1. Three ideal types of Instagram photography in the Instagram takeover project.

\begin{tabular}{|c|c|c|c|}
\hline Event/ideal type & The Acting Tourist & The Instagrammer & The Professional \\
\hline Planning & $\begin{array}{l}\text { Sharing delights for } \\
\text { tourists and citizens }\end{array}$ & $\begin{array}{l}\text { Sharing personal moments } \\
\text { with other citizens }\end{array}$ & $\begin{array}{l}\text { Sharing self-perceived } \\
\text { interesting aspects }\end{array}$ \\
\hline Shooting & Past temporal orientation & $\begin{array}{l}\text { Instant temporal } \\
\text { orientation }\end{array}$ & $\begin{array}{l}\text { Mix of different temporal } \\
\text { orientations }\end{array}$ \\
\hline Behind shooting & Postcard aesthetics & Authenticity & Complexity \\
\hline Editing & $\begin{array}{l}\text { Instagram filters to } \\
\text { enhance color and contrast }\end{array}$ & $\begin{array}{l}\text { Filters to express } \\
\text { atmosphere and mood }\end{array}$ & $\begin{array}{l}\text { Technically advanced } \\
\text { filters }\end{array}$ \\
\hline Display & $\begin{array}{l}\text { Many photographs } \\
\text { Indicative text-selective } \\
\text { of followers }\end{array}$ & $\begin{array}{l}\text { Few, selected photographs } \\
\text { Geo- and \#hash tags- } \\
\text { strive for "likes" and } \\
\text { followers }\end{array}$ & $\begin{array}{l}\text { Many photographs } \\
\text { personal \#hashtags- } \\
\text { ignorant of number of } \\
\text { followers and "likes" }\end{array}$ \\
\hline
\end{tabular}


city were choreographed according to social conventions of what was considered appropriate to post on the social media platform and participants' own strategic rationales of participating in the project. Typical rationales of participation were to counter a negative image of the city in the news media and promote themselves or their businesses. In addition, photographic conventions and the logic of the visual social media platform influenced the way the city was imaged. It is the ideal, positive, well-known, beautiful and impersonal image of the city that is displayed on Instagram. The logic of the platform to accrue likes and followers results in aspirational photographs and imaginaries. This means that to use Instagram takeovers in a place branding strategy for the purpose of reinvigorating the city image is difficult. While Instagram takeovers are useful to strengthen an already existing image of the city, this strategy is not likely to change or contribute to novel ways of imagining the city.

\section{Conflict of Interests}

The authors declare no conflict of interests.

\section{References}

Aronovitch, H. (2012). Interpreting Weber's ideal types. Philosophy of the Social Sciences, 42(3), 356-369.

Braun, E., Kavaratzis, M., \& Zenker, S. (2013). My cityMy brand: The different roles of residents in place branding. Journal of Place Management and Development, 6(1), 18-28.

Chalfen, R. (1987). Snapshot versions of Life. Bowling Green, $\mathrm{OH}$ : Popular Press.

Chalfen, R. (2002). Snapshots " $r$ " us: The evidentiary problematic of home media. Visual Studies, 17(1), 141-149.

Clark-Ibanez, M. (2004). Framing the social world with photo-elicitation interviews. American Behavioral Scientists, 47(12), 1507-1527.

De Certeau, M. (1984). The practice of everyday life. Berkeley, CA: University of California Press.

Dinhopl, A., \& Gretzel, U. (2016). Selfie-taking as touristic looking. Annals of Tourism Research, 57, 126-139.

Edensor, T. (2001). Performing tourism, staging tourism: (Re)producing tourist space and practice. Tourist Studies, 1, 59-81.

Gomez Cruz, E., \& Lehmuskallio, A. (2016). (Eds.). Digital photography and everyday life. London: Routledge.

Halkier, B. (2011). Methodological practicalities in analytic generalization. Qualitative Inquiry, 17(9), 787-797.
Kavaratzis, M. (2009). Cities and their brands: Lessons from corporate branding. Place Branding and Public Diplomacy, 5(1), 26-37.

Larsen, J. (2008). Practices and flows of digital photography: An ethnographic framework. Mobilities, 3(1), 141-160.

Orlikowski, W. J. (2007). Sociomaterial practices: Exploring technology at work. Organization Studies, 28(9), 1435-1448.

Pink, S. (2011). Amateur photographic practice, collective representation and the constitution of place. $\mathrm{Vi}$ sual Studies, 26(2), 92-101.

Postill, J. (2010). Introduction. In B. Bräuchler \& J. Postill (Eds.), Theorising media and practice (pp. 1-26). Oxford and New York, NY: Berghahn.

Reckwitz, A. (2002). Toward a theory of social practices: A development in culturalist theorizing. European Journal of Social Theory, 5(2), 243-263.

Schatzki, T. (1996). Social practices: A Wittgensteinian approach to human activity and the social. Cambridge: Cambridge University Press.

Shove, E., Watson, M., Hand, M., \& Ingram, J. (2007). The design of everyday life. New York, NY: Berg.

Spiggle, S. (1994). Analysis and interpretation of qualitative data in consumer research. The Journal of Consumer Research, 21(3), 491-503.

Thrift, N. (1999). The place of complexity. Theory, Culture \& Society, 16(3), 31-69.

Uimonen, P. (2013). Visual identity in Facebook. Visual Studies, 28(2), 122-135.

Van House, N. A. (2009). Collocated photo sharing, story-telling, and the performance of self. International Journal of Human Computer Studies, 67(12), 1073-1086.

Van House, N. A. (2011). Personal photography, digital technologies and the uses of the Visual. Visual Studies, 26(2), 125-134.

Van House, N. A. (2016). Outlook; Photographic wayfaring, now and to come. In E. Gomez Cruz \& A. Lehmuskallio (Eds.), Digital photography and everyday life (pp. 274-283). London: Routledge.

Warnaby, G. (2015). Rethinking the visual communication of the place brand: A contemporary role for chorography? In M. Kavaratzis, G. Warnaby, \& G. J. Ashworth (Eds.), Rethinking place branding, comprehensive brand development of cities and regions (pp. 175-190). Heidelberg, New York, NY, Dordrecht and London: Springer.

Zappavigna, M. (2016). Social media photography: Construing subjectivity in Instagram images. Visual Communication, 15(3), 271-289. 


\section{About the Authors}

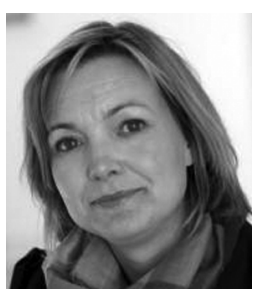

Åsa Thelander is Associate Professor in Media and Communication studies. She is currently working at the Department of Strategic Communication at Lund University, Sweden. Her research interests include visual communication, visual studies, strategic communication, digital media and qualitative methods.

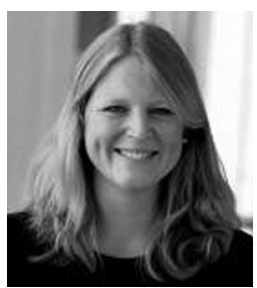

Cecilia Cassinger obtained her PhD from Lund University. At present she is senior lecturer at the Department of Strategic Communication, Lund University. Her research areas include place branding, marketing communication, digital media and culture, and collaborative forms of value creation. 